\title{
Impediments of Supply Chain Management Application in Readymade Garments Industry of Bangladesh
}

\author{
AHM Yeaseen Chowdhury ${ }^{1}$
}

Nazrul Islam ${ }^{2}$

Md. Zahedul Alam³

\section{Article History \\ Received 15 April 2019 \\ Reviewed 28 April 2019 \\ Revised 24 May 2019 \\ Accepted 28 May 2019}

\section{Keywords}

supply chain

management, political

instability, collaboration, workplace safety, employment opportunity

Journal of Business and Social Sciences Research (ISSN: 25422812). Vol IV, No. 1, June 2019

\begin{abstract}
There is a paramount importance of the Readymade Garments (RMG) industry of Bangladesh as it is the highest contributor in earning foreign exchange for the country. But the industry is facing stiff competition from other RMG producing countries including China, India, and Sri Lanka of the world. Hence, competitiveness especially at the manufacturing level became important for this industry. An efficient Supply Chain Management can increase the competitiveness and the satisfaction of the customers. Nowadays, SCM plays an integral part of a firm's success as it allows firms to quickly deliver products to the end-user for a low cost. Hence, RMG companies have very limited options other than implementing SCM as a strategy in order to remain competitive. This study intends to identify the impediments in applying sound SCM in the RMG industry. A mixed research method with a questionnaire survey has been employed for determining the impediments objectively. Use of descriptive analysis and Kendall Coefficient of Concordance have been made for ranking the challenges. This study found workplace safety, unavailability of raw materials and political instability are the major impediments for SCM applications in the RMG industry of Bangladesh.
\end{abstract}

\footnotetext{
${ }^{1}$ Associate Professor, Faculty of Business Studies, Bangladesh University of Professionals, Dhaka, Bangladesh. Email: yeaseenchy@bup.edu.bd

${ }^{2}$ Professor and Dean, School of Business, Canadian University of Bangladesh, Dhaka, Bangladesh. Email: nazrulku@gmail.com

${ }^{3}$ Associate Professor, Department of Marketing, Bangladesh University of Professionals, Dhaka, Bangladesh.Email: zalam@bup.edu.bd
} 


\section{Introduction and Study Objectives}

Bangladesh Readymade Garments (RMG) industry has become a lifeline for the growth of Bangladesh economy. It steers the Bangladeshi economy for graduating itself to a middle-income economy from a lower middle-income economy. The industry contributes 83.49 per cent of total export and employs more than four million people with 80 per cent female workers in more than 4500 companies (BGMEA Web Portal, 2019). Moreover, the industry has set a goal of USD 50 billion export by 2021. As the industry lacks competitiveness in terms of lead time, cost, quality, delivery dependability compared with other RMG producing nations, it must implement sound SCM practices. After lifting of The Multi-Fibre Arrangement (MFA), the problem becomes acute (Asgari \& Hoque, 2013). MFA is a quota system introduced by the US federal government for improving competitiveness of few RMG producing countries. In this backdrop, identifying the impediments of sound SCM application in the RMG industry would facilitate proper implementation of it. SCM plays a vital role in managing supply chain partners effectively for different companies (Fynes et al., 2008; Sambasivanet al., 2013). Thus, the study is a very time demanding one that would contribute in proper implementation of SCM in order to improve competitiveness.

After the setback incident of Rana Plaza, Tazrin Fashion fire incident and Holey Artisan Bakery buyers across the world heightened the compliance requirement (Rayhan, 2016). Buyers continue trading with a number of countries at the same time as practice. Bangladesh lacks in meeting lead time especially for trendy products. Different countries across the world enjoy different competitive advantages in terms of cost, availability of input materials, productivity, lead time, quality etc. A supply chain consists of components including facilities, functions and activities that are involved in producing and delivering a product from supplier(s) to customer(s) (Gonzales, 2001). The level of implementation of SCM in the industry is not satisfactory. There are a number of impediments in such implementation of SCM in the industry. It is evidenced from prior literatures that Bangladesh could recoup benefit in fostering productivity through effective implementation of SCM by removing different impediments. Usually, companies strive for increasing efficiency ignoring the importance of other partners of the supply chain (Power et al., 2001). It can be put that companies generally practise a quarter supply chain instead of extended supply chain. The extended supply chain concept reflects an end to end process; Suppliers' supplier in the upstream and customers' customers in the downstream.

This study investigated following objectives:

> To assess the present state of RMG industry of Bangladesh;

To evaluate the SCM practices in RMG industry of Bangladesh; and

> To identify impediments of efficient applications of SCM in the RMG industry of Bangladesh 
Impediments of Supply Chain Management Application in ... : Chowdhury, Islam, Alam

\section{Literature Review}

\subsection{Present State of Bangladesh RMG Industry}

Beginning its journey in the 80s with few companies, the RMG industry has grown hugely contributing the highest export earnings for the country. It is the second biggest RMG exporting nation after China. After MFA and Generalized System of Preference (GSP) have become defunct, the industry started losing order from buyers due to heavy competition (Joardar, 2016). The industry employs around 4 million people with 80 per cent of them being women with improved empowerment. However, it started facing difficulties from 2010 and the same aggravated further in 2013. Buyers continued increasing compliance requirements with no increase of corresponding price left the industry in a far more distressed situation. In this crisis situation, entrepreneurs are reluctant to come up with new investment and ventures in this industry (Hossain, 2016). More than 95 per cent of those firms are locally owned with the exception of a few foreign firms located in export processing zones (Gonzales, 2002). The sector accounts for 81 per cent of total export earnings of the country (BGMEA, 2017). The industry comprising both woven and knit started with an export earnings of only USD 1886.42 million in 1994 whereas an increasing trend ended up with USD 28.66 billion in 2016. Transition from resource-based export manufacturing to process based exports was the trend in the last two decades. Moreover, the Bangladesh government is providing required support in terms of policy, soft loan, incentive and bailout program constantly for sustainable growth of the industry.

\subsection{SCM Practices: Bangladesh RMG Sector}

The SCM practices in Bangladesh RMG sector is not up to the mark. Concerned people including owners are yet not very aware of the importance of SCM for improving operational and organizational performance. Very few companies in the industry have an SC department and started functioning not long ago. The average age of these newly introduced departments is only between 2 and 5 years. That too, the SCM performance level varies amongst companies depending on the emphasis owners and managers put into it. It can be generalized that with the effective implementation of SCM in the industry, targeted dividend can very well be achieved. This industry in Bangladesh is import based for input materials mostly fabrics of all kinds with exception of few accessories. Due to import dependency, Bangladesh RMG has a longer lead time than many RMG producing nations which is considered the single most important barrier for the industry (Rahman \& Anwar, 2006; Kabir, 2007). Buyers, in general, prefer those suppliers who have shorter lead time. The industry has great potential with effective implementation of selected SCM practices. Decision makers still think implantation of SCM is an additional and less important investment. Instead considering it to be strategic tools for improving performance, it is sometimes considered as a cost centre. 
Nuruzzaman (2009) stated that Bangladesh RMG included components like Supplier, Garment Industries, Individuals, Buyers, Raw Materials, Finished Goods, and Payment. In general, an SC includes parties involved in one way or the other that add value in the process for meeting customer requirements. Customers are in the forefront of the present days' SCM. SCM ensures effective flow of products, services, information and funds between suppliers and customers. But however, Tanvir and Muqaddim (2013) argued that the SCM of the RMG sector is more critical due to global connectivity and uncertainty. Companies are still sourcing input materials from the same countries out of habit as their predecessors used to do. No initiative is visible where they are striving for new suppliers for input materials. Agami (2012) argued that through effective implementation of SCM companies can save cost from sourcing input materials through effective purchasing and can become cost leaders thus they can create value for money for the customers.

Besides common players in the extended SC of a typical company, there are support functions including 3 and $4 \mathrm{PL}$, appropriate information technology, port facilities as well in the chain. All components need to act in a well-orchestrated manner for deriving expected result and output. Berg et al. (2011) identified low supplier and labour efficiency, compliance issues, weak infrastructures, insufficient backward linkage and political volatility as the barriers for SCM implantation of Bangladesh RMG sector. Bangladesh is facing acute problems as buyers are shifting their choices from low cost RMG products to shortened lead time, timely delivery, and efficient responses on change in design and so on. The industry can meet these challenging demands by customers through efficient implementation of SCM.

SCM lacks a common definition because of its multidisciplinary origin. International Chamber of Commerce defined SCM as the acquisition, transformation and delivery processes with flows of information \& funds from suppliers to the end customers. On the other hand, the Council of Logistics Management (2000) defines SCM as the systematic and strategic tools for improving long term performance of the organizations. The concept of SCM is not very old, it only started in the early 80 s but the underlying issues were age old. It only transformed from other traditional functions for taking its presentday shape. In this era of competition, now companies do not compete with companies rather SCM makes the difference. People around the world started realizing the importance of SCM in the organizations for recouping expected benefit (Power et al., 2001; Li et al., 2005). On the contrary, Chen and Paulraj (2004) described SCM with the idea that companies are working as the part of value adding units in the chain. Basak et Al., (2016) conducted a study in Bangladesh RMG industry and found that all the parties involved in extended SC should collaborate with each other both vertically and horizontally for such benefit. 
There are several studies conducted for ascertaining the impediments for implementation of SCM in the RMG sector of Bangladesh. Customers in this sector are becoming more and more time sensitive over the last decade. They put shorter delivery and cycle time as the priority one over cost and quality though they don't want to make any compromise in other selection criteria as well (Asgari \& Hoque, 2013). Bangladesh RMG must strive for reducing cycle time, improve quality and reduce associated cost for winning increased levels of orders from the prospective buyers. Integrated SCM implementation is a likely solution to the problem Bangladesh RMG is facing now. Hossain and Roy (2013) found wages, effective SCM, compliance requirements as the most important features of the RMG sector in one of their studies. On the other hand, Tanvir and Muqaddin (2013) found SCM as the critical and success factor for the companies in the industry. Shahriar et al. (2014) concluded that effective SCM would encourage both effectiveness and efficiency in the RMG sector if implemented judiciously. Further, Islam and Liang (2015) found in a study conducted on RMG industry of Bangladesh that import dependency for fabrics and other required inputs are the main reasons for long cycle time and onward delivery schedule and lead time. Bangladesh RMG industry must gradually decrease such dependency through improving backward linkage, should it want to become competitive in the globe.

Agami et al. (2012) used financial and non-financial performance measures for evaluating SCM efficiency in the manufacturing industry in the US. They argued that SCM efficiency is of utmost importance for improving organizational and operation performance for any kind of organization.

Razzaque (1997) conducted a study in Bangladesh RMG industry in order to find the likely challenges of logistics management. He argued that besides few other barriers of efficient logistics management, the unwilling mind set of the owners takes the driving seat in such inefficient logistics management. Kader and Akter (2014) argued that import dependency and inefficient flow of information are the challenges of longer lead time of Bangladesh RMG industry. Improving on these issues, the industry can expect to shorten their cycle time for competing with other RMG producing nations in the world. Lower inventories, lower costs, higher productivity, greater productivity, greater agility, shorter lead times, higher profits and greater customer loyalty are few of the main components of the effective SCM for the RMG industry (Ali \& Habib, 2012). In an attempt to bridge the research gap so identified through exhaustive literature reviewto find the impediments of efficient application of SCM in the Bangladesh RMG industry for becoming competitive.

\section{Research Methods}

A mixed research method; qualitative and quantitative has been employed for this research. Questionnaire survey comprising both open and close ended questions was also administered among a representative sample who were 
mostly executives and managers working in the SCM department of the sample companies. The study used a cluster and stratified representative sampling procedure where Ashulia, Savar, Gazipur (located in outskirt of Dhaka city) and Banani (within Dhaka city) were the clusters and size of the firms (large, medium and small) is the strata. One hundred companies with large, medium and small companies were selected through following sample determining formula:

$\mathrm{n}=\frac{N Z^{2} p q}{N d^{2}+Z^{2} p q}=100$.

Out of this 100 sample companies 30 per cent each is large and medium companies and 40 per cent is small companies. On the other hand, 399 respondents have been selected for collecting required primary data through using the formula by Krejcie and Morgan (1970) that follows:

$$
n=\frac{X^{2} \times N \times P \times(1-P)}{\left(M^{2} \times(N-1)+\left(X^{2} \times P \times(1-P)\right.\right.}=399 .
$$

This study used both primary and secondary data for necessary analysis in order to find out the impediments of SCM application in the industry. Primary data was collected through survey as mentioned above and for the secondary data relevant literatures, Articles, BGMEA reports were also consulted. A scoring model was used with lowest total score against any impediment becomes the first rank and vice versa. Once the impediments were ranked through using score model so adopted, Kendall coefficient of concordance was also used for finding any potential intermingling associations among the impediments so identified.

\subsection{Hypothesis for the Study}

The following hypothesis has been selected for this study to find out the association among the different impediments identified:

$\mathrm{H}_{0}$ : No association exists amongst the ranks in impediments of efficient application of SCM in the RMG industry of Bangladesh.

$\mathrm{H}_{\mathrm{A}}$ : Association exists amongst the ranks in impediments of efficient application of SCM in the RMG industry of Bangladesh.

\section{Data Analysis and Discussions}

Few of the challenges prior studies identified for Bangladesh RMG sector are: Backward Linkage, Buying Behaviour, Inefficient Planning, Lack of Safety Measures, Lack of Advanced Production Systems, Productivity Challenges, Weak Infrastructure, Lack of Deep-Sea Harbour, Poor Port Facility, Labour Unrest, Political Tensions, Security Issues, Lack of Automation, Increased cost of 
Manufacturing etc. For this particular study 15 such most important and relevant impediments have been considered after consulting with owners, BGMEA officials and SCM professionals. Responses were obtained through a structured questionnaire with 5-point Likert scale. Descriptive analysis was made and the summary of the result has been given in Appendix 1 .

Descriptive analysis and Kendall coefficient of concordance were used for carrying out necessary statistical analysis for obtained ranked data. Safety Issue topped the chart with number 1 rank among other impediments identified for the RMG sector of Bangladesh. Import dependency for the fabrics is the second most important impediment whereas Inefficiency of workers and political instability have been identified as Third and fourth ranked impediment for efficient application of SCM in the Bangladesh RMG sector. Labour unrest and lack of training of personnel in the RMG sector have been identified as fifth and seventh ranked impediments for implementation of SCM. On the other hand, incompetent ports entry, loading unloading time custom clearance and poor government policy have been identified as seventh, eighth, nineth and tenth ranked impediments.

After critically evaluating all the useful tools for non-parametric tests, use of Kendall Coefficient of Concordance (W) was made. The data so obtained were firstly arranged into $\mathrm{K} \times \mathrm{N}$ Table (Appendix - 2). Column getting the lowest value was ranked first and the column getting highest value was ranked last. The critical value of $c^{2}$ with 14 (degree of freedom) and at 0.001 level of significance is 29.141 suggesting that $H_{0}$ is rejected. There is no statistically good reason to reject alternative hypothesis $\left(\mathrm{H}_{1}\right)$ and simply means that there is good association among the ranks of causes of poor application of SCM in RMG industry of Bangladesh and the association is significant at 0.001 level of significance.

\section{Conclusion and Implications}

Buyers across the world are imposing more and more compliance requirements after a few unexpected incidents which leaves the industry in more distressed situations than ever before. Bangladesh must implement proper SCM for improving competitiveness through addressing all the compliance requirements. The lead time remains the most important factor that companies in the industry immediately address for remaining competitive. In doing so, the industry must reduce dependency on imports for fabrics by improving the textile industry. Ensuring quality of products is another factor that the industry should consider. There were very scanty prior studies available in trying to ascertain the impediments of poor SCM application in the industry. But over the last decades these impediments so identified changed their priority and order depending on the changed preference by buyers and the situation of the competitive environment. More and more countries are being added in the list of RMG producing nations. The decision makers must first know the impediments along with priority and order in terms of ranking in 
order to address all these issues as a priority basis to achieve a target export of USD 50 billion by 2021. After the lifting of GSP and MFA facilities, the industry has been put into stiff competition from China, Cambodia, Sri Lanka and Ethiopia. The congestion in Chittagong sea port has added additional fuel for inefficient application of SCM in the industry. The study found that safety issues, unavailability of fabrics, inefficiency of workers, political instability and labour unrest are the top five impediments for efficient application of SCM in the industry. This study identified impediments with ranking that will help policy makers in taking timely measures for turning the industry competitive.

After necessary analysis of data obtained and critical evaluation of prior literatures, this study makes following recommendations:

> Bangladesh Garments Manufacturers and Exporters Association (BGMEA) and government should facilitate RMG companies for meeting compliance requirements imposed by buyers and all concerned should also engage with buyers for obtaining confidence.

The industry should reduce import dependency for fabrics and all stakeholders must come forward for improving textile sector through policy and soft funding support.

$>$ All political parties should come to a consensus for brining political stability in the country through becoming more democratic.

\section{References}

Agami et al. (2012). Supply chain performance measurement approaches: Review and classification. Journal of Organizational Management Studies: $10.5171 / 2012.872753$

Ali, M., \& Habib, M. M. (2012). Supply chain management of textile industry: A case study on Bangladesh. Int. J Sup. Chain. Mgt,1(2).

Asgari, B., \& Hoque, A. (2013). Lead-time management in Bangladesh garments industry: A system dynamics exploration. Asia Pacific Business \& Economics Perspectives, 1(2).

Basak,A.(2016). Importance of human resource management and the competitive advantage: A case analysis on basis of the textile industry of Bangladesh. Global Journal of Management and Business Research: Administration and Management, 14(9), 93-115.

Berg, D., Brockmann, K., Srulijes, K., Hauser, A.-K., Schulte, C., Csoti, I., \& Gasser, T. (2011). GBA-associated PD presents with non-motor characteristics. Neurology, 77(3).

BGMEA Web Portal (2019). Webportal of Bangladesh Garments Manufacturers and Exporters Association, Bangladesh

Fynes.B., Eamonn, A., \& Daniel, L. (2008). Communication media selection in 
Impediments of Supply Chain Management Application in ... : Chowdhury, Islam, Alam

buyer-supplier relationships. International Journal of Operations and Production Management, 28(4).

Gonzales, P. M. (2002). The effects of stereotype threat and double-minority status on the test performance of Latino women. Personality and Social Psychology Bulletin, 28(5).

Hossain. Md. U,, \& Roy, I.. (2016). Supply chain management for sustainable RMG growth in Bangladesh. International Journal of Science and Research (IJSR), $5(4)$.

Islam. Md. S., \& Liang, G.Q. (2015). Supply chain management on apparel order process: A case study in Bangladesh garment industry. Asian Journal of Business and Management Sciences, 2 (8),60-72.

Joardar, M. (2016). Post-MFA performance of Bangladesh apparel sector. International Review of Business Research Papers, 6(4). 134 - 144.

Kader, S., \& Akter, M. M. K. (2014). Analysis of the factors affecting the lead time for export of readymade apparels from Bangladesh; proposals for strategic reduction of lead time. European Scientific Journal, 10.

Krejcie \& Morgan. (1970). Determining sample size for research activities. Educational and Psychological Measurement, 30, 607-610.

Li, S., Ragu-Nathan, B., Ragu-Nathan, T.S., \& Rao, S. S. (2005). Development and validation of a measurement instrument for studying supply chain management practices. Journal of Operations Management, 23, 618-641.

Nuruzzaman, M., \& Haque, A. (2009). Lead time management in the garment sector of Bangladesh: An avenue for survival and growth. European Journal of Scientific Research, 33( 4), 617-629.

Paulraj, A., \& Chen, I. J. (2004). Understanding supply chain management: Critical research and a theoretical. International Journal of Production Research, 42(1), 131-163.

Power, D J., Sohal, A., \& Rahman, S.U. (2001). Critical success factors in agile supply chain management: An empirical study. International Journal of Physical Distribution and Logistics Management, 31 (4), 247-265.

Rahman, M., \& Anwar, M.A. (2006). Glucose oxidase immobilization on a novel cellulose acetate-polymethyl methacrylate membrane. Journal of Biotechnology, 121(3), 351-360.

Rayhan, Md. Z. (2016). The competitiveness of RMG industry of Bangladesh after some tragic incidents: An overview of the present compliance practice at RMG sector of Bangladesh. Research Journal of Social Science and Management, $5(10)$.

Razzaque, Md. A. (1997). Challenges to logistics development: The case of a Third World country - Bangladesh. International Journal of Physical Distribution \& Logistics Management, 27(1), 18-38. 
Shahriar et al. (2014). A research framework of supply chain management in readymade garments industry of Bangladesh. International Journal of Business and Economics Research, 3(6), 38-44.

Swamidass, P. M. (2000). Encyclopedia of production and manufacturing management.

Tanvir, S.I., \&Muqaddim, N. (2013). Supply chain management offering the new paradigm for Bangladesh garment industry. Journal of Economics and Sustainable Development, 4(20).

World Bank. (2005). Country brief., Dhaka: Author.

\section{Conflict of interest}

The authors claim that they have no conflict of interest in the research work. 
Impediments of Supply Chain Management Application in ... : Chowdhury, Islam, Alam

\section{Appendix 1}

Descriptive Analysis

\begin{tabular}{lccccc}
\hline $\begin{array}{c}\text { SCM Impediments Used } \\
\text { for the Study }\end{array}$ & Mean & Std. Deviation & $\begin{array}{c}\text { Score } \\
\text { Obtained }\end{array}$ & $\begin{array}{c}\text { Freq with } \\
\text { Highest Priority }\end{array}$ & Rank \\
\hline 1. Workplace safety & 1.39 & 0.55 & 554 & 254 & 1 \\
2. Availability of rawmaterials & 2.33 & 0.93 & 928 & 63 & 2 \\
3. Inefficiency of the workers & 3.75 & 0.92 & 1496 & 11 & 3 \\
4. Political instability & 3.82 & 2.11 & 1524 & 45 & 4 \\
5. Laborunrest & 4.67 & 1.2 & 1865 & 12 & 5 \\
6. Lack of training & 6.64 & 1.05 & 2651 & & 6 \\
7. Incompetent ports entry & 7.93 & 0.96 & 3165 & & 7 \\
8. Load-unload time & 8.15 & 2.62 & 3251 & 6 & 8 \\
9. Custom clearance & 8.35 & 2.47 & 3331 & 13 & 9 \\
10. Poor govt. policy & 8.54 & 0.89 & 3409 & & 10 \\
11. Diesel and power & 12.09 & 1.88 & 4523 & 1 & 11 \\
12. Insufficiency of loan & 12.9 & 1.29 & 5146 & 2 & 12 \\
13. Lack of marketing tactics & 13.09 & 1.02 & 5223 & & 13 \\
14. Managers, approach & 13.22 & 2.01 & 5274 & & 14 \\
15. Blending procedures & 13.23 & 1.92 & 5279 & & 15 \\
\hline
\end{tabular}

Source: Survey Data 


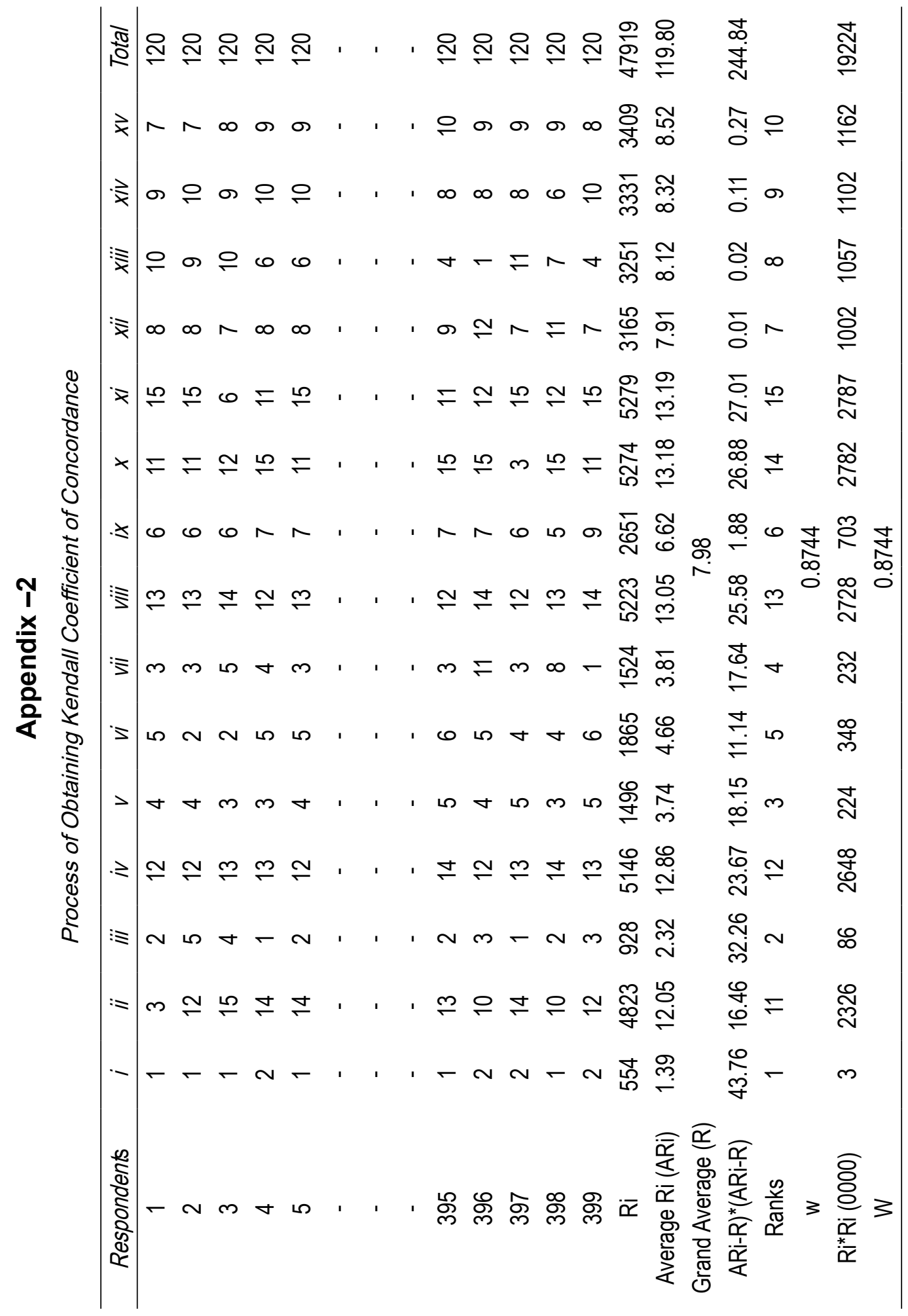

